\title{
MATERNAL SMOKING DURING PREGNANCY AND CHRONIC HEADACHE AT SCHOOLCHILDREN
}

\author{
C.E. Fabbri ${ }^{1}$, M.A. Barbieri ${ }^{1}$, A.A. da Silva $^{2}$, M.R. Gutierrez ${ }^{1}$, H. Bettiol ${ }^{1}$, J.G. Specialli ${ }^{3}$, R. Rona ${ }^{4}$ \\ ${ }^{I}$ Puericultura e Pediatria, Faculdade de Medicina de Ribeirão Preto, Universidade de São Paulo (FMRP- \\ USP), Ribeirao Preto, ${ }^{2}$ Departamento de Saude Publica, Facudade de Medicina de Sao Luis, Sao Luis, \\ ${ }^{3}$ Neurociencias e Ciencia do Comportamento, Faculdade de Medicina de Ribeirão Preto, Universidade de \\ São Paulo (FMRP-USP), Ribeirao Preto, Brazil, ${ }^{4}$ Department of Psychological Medicine, King's College \\ London, London, UK
}

Objective: Current tobacco smoking has been associated with headache. However it is not known if maternal smoking during pregnancy is associated with headache in their offspring. The aim of this research was evaluated the association between maternal smoking during pregnancy with headache in schol-aged children.

Methods: Two prospective cohorts of 869 children aged 10-11 years from Ribeirao Preto (SP- Brazil) and 805 children aged 7-8 years from Sao Luis (MA- Brazil) were studied. Data on maternal smoking were collected at birth and data on headache and other confounding factors were collected at schol age using the same questionnaire completed by the mothers in the two cities. Primary headache was defined as a mother reporting that his/her child had $\geq 2$ episodes of headache in the two last weeks, without any associated organic symtoms. The prevalence Rate Ratio (PRR) and its $95 \%$ confidence interval $(95 \% \mathrm{CI})$ were calculated by Poisson regression.

Results: Prevalence of headache was reported by the mother was $28.2 \%$ in RP and $12.8 \%$ in SL. After adjustment, children whose mothers smoked $>=10$ cigarettes per dayduring the pregnancy presented higher prevalence of primary headache than their counterparts in both cohorts (PRR=1.63, 95\%CI 1.10-2.42 in RP and $\mathrm{PRR}=2.98,95 \% \mathrm{CI} 1.34-6.63$ in SL).

Conclusions: In spite of adjusting for a long list of potential confounders, maternalsmoking during pregnancy was associated with headache in 7-11 years olds in two Brazilian cities of contrasting economic wealth. 